\title{
Estratégia\&Negócios
}

ISSN 1984-3372

http://www.portaldeperiodicos.unisul.br/index.php/EeN/

\section{PERCEPÇÃO DA ESTRATÉGIA DE EXTENSÃO DE MARCA EM ESTABELECIMENTOS COMERCIAIS: QUAL O MELHOR NOME PARA UMA LOJA?}

\section{BRAND EXTENSION STRATEGY PERCEPTION IN COMMERCIAL ESTABLISHMENTS: WHAT'S THE BEST NAME FOR A STORE?}

\section{Evandro Luiz Lopes}

Doutorado e Mestrado em Administração de Empresas pela Universidade Nove de Julho - São Paulo.

E-mail: elldijo@uol.com.br

José Mauro Costa Hernandez

Centro Universitário da FEI.

E-mail: imhernandez@uol.com.br

Recebido em 06/07/2012. Aprovado em 07/03/2013. Disponibilizado em 05/05/2013. Avaliado pelo Sistema double blind review

R. eletr. estrat. neg., Florianópolis, v.6, n.1, p. 108-133, jan./abr. 2013 http://portaldeperiodicos.unisul.br/index.php/EeN/index
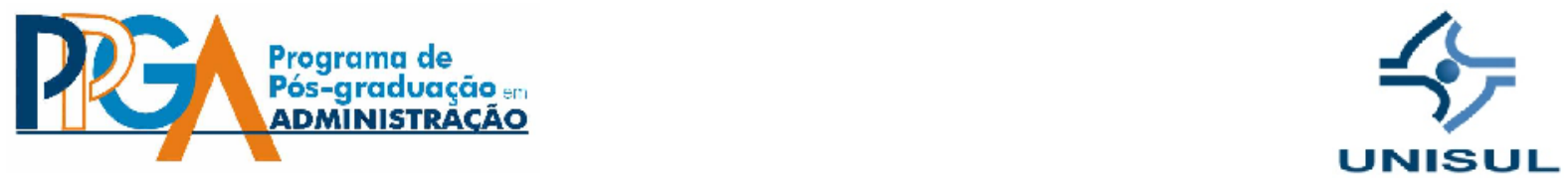

CCopyright 2008 UNISUL-PPGA/Estratégia e Negócios. Todos os direitos reservados. Permitida citação parcial, desde que identificada a fonte. Proibida a reprodução total. Em caso de dúvidas, consulte o editor: ademar.unisul@gmail.com; (48) 3229-1932. 


\section{RESUMO}

O objetivo principal deste estudo é verificar qual o efeito que diferentes estratégias de atribuição de um nome de marca (carregado de significado ou inventado) exercem sobre extensões de marcas varejistas mais e menos similares. Esta pesquisa se justifica tanto pela ausência de estudos sobre extensão de marcas varejistas quanto pela recorrência com que essa estratégia vem acontecendo em nossa sociedade. As hipóteses formuladas foram testadas por meio de um experimento, concebido com a projeção de cenários, em desenho fatorial completo 3 (alta, média e baixa similaridade entre formato varejista original e estendido) $\times 2$ (nome carregado de significado e nome inventado) entre sujeitos, que envolveu 170 respondentes. 0 resultado deste estudo indica que a utilização de nome carregado de significado não parece ser adequada para extensão em formatos com baixa similaridade em relação ao formato original, e também que a extensão de nome carregado de significado se mostrou uma boa opção para novos negócios similares ao formato original do varejista.

Palavras chave: Extensão de marca. Varejo. Similaridade.

\section{INTRODUÇÃO}

A extensão de marca é uma estratégia utilizada pelos gestores de marketing para capitalizar, em um novo produto, a força da marca de um produto já existente. Keller (1993, p. 154) define-a como "[...] a prática de usar um nome de marca atual para entrar em uma classe de produto completamente diferente". Um exemplo dessa estratégia é a utilização da marca Alpino, usada primeiramente pela Nestlé para dar nome a um chocolate e, em seguida, como patrimônio para projetar uma linha de sorvetes.

As extensões de marca têm proliferado muito nas últimas décadas. Estudos de marketing identificaram que entre 80 e $90 \%$ dos produtos lançados anualmente utilizaram essa estratégia de branding (KELLER, 2003; VÖLCKNER; SATTLER, 2004).

No setor de serviços, o número de extensões pode ser ainda maior, se comparado com o setor industrial - fabricante de produtos tangíveis - uma vez que essas empresas tendem a usar 
uma marca única, na qual todas as ofertas de serviços são agrupadas, geralmente sob a mesma razão social (FREE, 1996).

A ampla utilização da extensão de marca deve-se principalmente aos benefícios que a marca mãe confere à sua extensão (KELLER, 2003). Por um lado, os produtos comercializados sob uma marca conhecida são mais atraentes para os consumidores (AAKER; KELLER, 1990; KELLER, 2003) e distribuidores (MILEWICZ; HERBIG, 1994) e conferem aos fabricantes e fornecedores de serviços a redução dos custos de comercialização, aumentando a probabilidade de sucesso (SULLIVAN, 1992; MORRIN, 1999). Por outro lado, as extensões podem incrementar as dimensões do brand equity (valor da marca), tais como imagem e reputação (MORRIN, 1999), e aumentar a possibilidade de compra de outros produtos da mesma marca, ou utilização de outros serviços do mesmo provedor (SWAMINATHAN; FOX; REDDY, 2001; CHEN; LIU, 2004), resultando no aumento do marketshare, na maximização da eficiência e na minimização de custos de propaganda e publicidade (SMITH; PARK, 1992).

Mesmo já tendo se passado mais de vinte anos desde os primeiros trabalhos relevantes sobre avaliação de extensão de marcas (BOUSH et al., 1987; AAKER; KELLER, 1990), parece ainda estar longe o consenso sobre quais variáveis são mais importantes e como elas interagem na opinião dos consumidores, pois são questionados os resultados de sua adoção, dadas as diversas situações em que a extensão de marca pode ocorrer; por exemplo, questiona-se como a extensão de marca traria melhores resultados: quando ela é associada ao produto (carregada de significado) ou quando o nome da marca é inventado (SWAMINATHAN, 2003).

Um nome carregado de significado é aquele que expressa informações relevantes sobre o produto que é comercializado com essa marca, como, por exemplo, Compre Bem ou Pegue \& Faça. Já um nome inventado não guarda nenhuma relação com o formato da loja ou com os produtos que ela comercializa, como em Pão de Açúcar ou Riachuelo (KOHLI; SURI, 2000).

Embora estudos anteriores tenham revelado que nomes carregados de significado sejam mais fáceis de lembrar e geralmente têm maior preferência dos consumidores em relação aos nomes inventados (KELLER; HECKLER; HOUSTON, 1998; KOHLI; SURI, 2000; KOHLI; HARICH; LEUTHESSER, 2004), um nome carregado de significado pode se tornar limitado a um determinado 
produto ou varejista, enquanto que um nome não relacionado pode ser aplicado e estendido a qualquer categoria de produto ou serviço (KELLER, 1993).

Especificamente, nossa hipótese é de que nomes carregados de significados resultem em avaliações melhores de extensões de marcas de serviços comerciais mais similares e que nomes inventados resultem em melhores avaliações de extensões menos similares.

Diante desse contexto, o propósito deste trabalho é, por meio de um experimento, verificar qual o efeito que diferentes estratégias de atribuição de um nome de marca (carregado de significado ou inventado) exercem sobre extensões de marcas varejistas mais e menos similares. Para tanto, este artigo foi estruturado em seis seções, incluindo esta breve introdução. A segunda seção traz o embasamento teórico que norteou a pesquisa e as hipóteses propostas, que foram testadas na etapa empírica. A seção seguinte descreve a metodologia utilizada na pesquisa de campo e na análise dos dados. A quarta seção divulga e discute os resultados encontrados. A quinta traz as limitações e sugestões para futuros estudos e, por fim, a sexta seção é dedicada às considerações finais dos autores.

\section{REFERENCIAL TEÓRICO}

\subsection{MARCA}

Para a American Marketing Association (AMA), marca é um nome, termo, símbolo, desenho ou uma combinação desses elementos, que tem a finalidade de identificar bens ou serviços de um fornecedor ou grupo de fornecedores e diferenciá-los da concorrência (AMA, 2009).

Segundo Keller (1998), as marcas assumem diferentes significados para fabricantes e consumidores. Para os fabricantes ou provedores de serviços, marca é o meio de proteger legalmente características específicas de produtos e serviços, sendo uma fonte de vantagem competitiva e de retornos financeiros. Já para os consumidores, a marca identifica a fonte do produtos ou serviços, determinando a responsabilidade dos provedores, podendo conferir-Ihes redução da percepção de risco e potencializar a percepção de qualidade (KELLER, 1998). 
Harmonizando a conceituação da AMA e o entendimento de Keller (1998), Aaker (1998) define marca como um nome diferenciado ou símbolo destinado a identificar os bens ou serviços de um vendedor, ou de um grupo de vendedores, e a diferenciar esses bens e serviços daqueles dos concorrentes. Assim, uma marca sinaliza ao consumidor a origem do produto ou serviço e protege tanto o consumidor quanto o fornecedor dos concorrentes que oferecem produtos ou serviços que pareçam idênticos.

\subsection{MARCAS ENQUANTO NOMES DE LOJAS}

Um dos desafios atuais do marketing é a atribuição de nomes adequados às marcas tanto para produtos como para provedores de serviços e seus respectivos estabelecimentos comerciais.

Os nomes das lojas, além do lado meramente referencial, desempenham uma função de apelo ao receptor, que só tem paralelo nos nomes das marcas dos produtos comerciais. Inserindo-se no campo do discurso publicitário, criatividade é a palavra-chave que se encontra na sua gênese. Do mesmo modo que o slogan, o nome da loja exige uma rápida captação sensorial e, simultaneamente, visa a uma forte interpelação ao público alvo e a uma inscrição permanente na sua memória coletiva (MOUTINHO; COIMBRA, 1998). A importância publicitária do nome de uma loja é de tal modo elevada que justifica a existência de diversas empresas especializadas na tarefa de atribuir nomes a empresas e produtos. Essas organizações se dispõem a criar nomes (como é o caso da empresa Metaphorname, disponível em: <www.metaphorname.com $>$ ), os quais poderão pertencer a uma de três categorias: a) descritivos - que descrevem literalmente a função/atividade da empresa; b) arbitrários - que utilizam palavras reais sem nenhum vínculo direto com a empresa/atividade comercial; ou c) genéricos - quando formados por palavras sem nenhum significado óbvio, de acordo com as estratégias pretendidas pelo cliente.

Estudos apontam que não há consenso entre acadêmicos e gestores de marketing quanto à forma de categorizar nomes, pois, segundo Meltom (1979, apud KOHLI, HARICH e LEUTHESSER, 2004), para os acadêmicos, a classificação deve ocorrer em dimensões como extensão, distinção, frequência de ocorrência e características linguísticas envolvidas, enquanto 
que os gerentes de marketing classificam esses nomes em uma graduação de cinco classes: genéricos, descritivos, sugestivos, arbitrários e inventados.

Kohli e Suri (2000), por sua vez, destacam duas abordagens para o processo de dar nomes às marcas. A primeira abordagem consiste em atribuir ao produto ou serviço um nome carregado de significado, ou seja, criar um nome que apresente informações relevantes sobre ele. Compre Bem Supermercados e Pegue \& Faça são, respectivamente, exemplos de marcas que reforçam a natureza e enfatizam um ou mais atributos do formato varejista.

A segunda abordagem consiste em atribuir ao produto ou serviço um nome não carregado de significado ou inventado, ou seja, um nome que tenha pouca ou nenhuma relação com o formato da loja ou com os produtos por ela comercializados (por exemplo, A Insinuante Eletrodomésticos), ou palavras que tenham sido criadas e não tenham significado semântico na língua do país em que a marca foi criada (por exemplo, Kalunga Materiais para Escritório e Khelf Confecções).

Um nome de marca carregado de significado transmite informações relevantes a respeito da loja (ou de um ou mais de seus atributos) e pode estabelecer uma conexão entre a loja e o seu formato ou aos produtos que comercializa mais rapidamente que uma marca não carregada de significado. Essa estratégia de naming, avaliam Kohli e Suri (2000), pode ser vantajosa durante o posicionamento inicial. É comum que, em certas ocasiões de compra, os consumidores busquem atalhos e tentem facilitar ao máximo o processo de tomada de decisão. Ao desconsiderar grande parte das informações disponíveis durante esse processo, os consumidores tornam esses nomes de marca inerentemente carregados de significados mais atrativos (o que pode resultar que, para um nome carregado de significado, seja menos dispendioso educar o comprador).

Em geral, estudos anteriores revelam que nomes carregados de significado são mais fáceis de lembrar e geralmente têm maior preferência dos consumidores em relação a nomes inventados (KELLER; HECKLER; HOUSTON, 1998; KOHLI; SURI, 2000; KOHLI; HARICH; LEUTHESSER, 2004). Em contrapartida, um nome carregado de significado pode se tornar limitado a um determinado produto ou varejista, enquanto um nome não relacionado pode ser aplicado e 
estendido a qualquer produto, categoria de produto (KELLER, 1993) ou estabelecimento comercial.

\subsection{A ESTRATÉGIA DA EXTENSÃO DE MARCA}

Entende-se que uma marca foi estendida quando ela é utilizada em produtos ou serviços de classe diferente daquela na qual é usualmente utilizada (SWAMINATHAN; FOX; REDDY, 2001). Esse é também o entendimento de Aaker (1998), quando afirma que a extensão de marca se dá a partir da utilização de um nome de marca já estabelecido em um mercado ou categoria de produtos em outros nos quais ainda não atua.

A extensão de uma marca pode ser utilizada tanto em produtos ou serviços intimamente relacionados com a marca-mãe - definidos na literatura de Marketing como produtos ou serviços com alta similaridade com a marca-mãe (AAKER; KELLER, 1990) - , como também em produtos ou serviços não diretamente relacionados à mesma classe de consumo, canais de distribuição ou comunicação - definidos como produtos ou serviços de baixa similaridade com a marca-mãe (AAKER; KELLER, 1990). Dentro deste continuum, a extensão de marca também pode ocorrer em situações de média similaridade percebida, quando a relação entre o formato original e o estendido não é tão óbvia quanto a verificada nas situações de alta similaridade e nem tão distante quanto nas extensões de baixa similaridade.

A literatura revela vários benefícios logrados pelas empresas na utilização da estratégia de extensão de marcas. Kapferer (2003) cita o aumento do impacto da propaganda sobre a marca, potencial redução de custos de veiculação de mídia, provável aumento dos espaços nos pontos de venda destinados aos produtos da empresa, diminuição dos custos de distribuição e a maior aceitabilidade dos novos produtos por parte dos varejistas, tendo em vista que os consumidores finais reconhecerão a marca de imediato.

Evidentemente, alguns riscos são assumidos quando um provedor de produtos ou serviços adota a estratégia de extensão de marca. Entende-se que os principais são a diluição do conceito individual do produto ou serviço, a diluição dos efeitos da propaganda e o risco de 
comprometer a marca, quando a extensão é realizada em um produto/serviço inadequado (KAPFERER, 2003; KELLER; MACHADO, 2006).

Os resultados da pesquisa sobre extensão de marca e os impactos na percepção dos consumidores, realizada por Aaker e Keller (1990), indicam que:

a) a transferência de atributos entre a marca-mãe e a extensão de marca pode ter efeitos tanto negativos como positivos. Quando há incongruência entre o atributo e o produto estendido, o consumidor tende a perceber a estratégia como negativa;

b) a percepção de qualidade entre a marca principal e a extensão é influenciada positivamente quando as categorias dos produtos apresentam uma natureza complementar;

c) quanto maior a percepção de qualidade a respeito da marca principal, maior a chance de o consumidor transferir as qualidades desta para suas extensões; e

d) atitudes positivas relacionadas à extensão de marca se relacionam com a similaridade desta com a marca principal na percepção do consumidor.

Diversos estudos já foram realizados, buscando melhorar o entendimento da extensão de marcas em produtos físicos, tanto na academia brasileira (OLIVEIRA; MATTAR, 2000; VELOSO, 2003; RIBEIRO, 2006; MARQUI; BATALHA; URDAN, 2008), como na americana (PARK; MILBERG; LAWSON, 1991; SWAMINATHAN; FOX; REDDY, 2001; ZHANG; SOOD, 2002). Porém, poucas foram as pesquisas sobre esse tema com o intuito de analisar os efeitos da extensão de marcas de estabelecimentos comerciais.

\subsection{FORMULAÇÃO DAS HIPÓTESES}

Como visto nas seções anteriores, a extensão de marca pode ser utilizada tanto em serviços intimamente relacionados com a marca-mãe (alta similaridade), como também em serviços não diretamente relacionados (baixa similaridade). Também já existe na literatura a indicação de que nomes carregados de significado permitem estabelecer rápida conexão entre a loja e seu formato, ou aos produtos que comercializa, e que nomes não carregados de significado 
permitem maior flexibilidade na aplicação de extensões de marca. Dessa forma, fica claro que o que irá constituir um nome adequado de marca dependerá dos objetivos traçados pela empresa para ela. Se o objetivo é alavancar o reconhecimento e o recall da marca, um nome carregado de significado mostrar-se-á mais indicado. Se o objetivo é favorecer a flexibilidade ou adaptabilidade de uma marca, nomes não relacionados serão preferidos. Diante desses pressupostos, formulamse as duas primeiras hipóteses a serem testadas:

Hipótese 1 - Extensões de marcas com nomes carregados de significado serão mais bem avaliadas que extensões de marcas com nomes inventados, quando a similaridade percebida entre a extensão e a marca-mãe for alta.

Hipótese 2 - Extensões de marcas com nomes inventados serão mais bem avaliadas que extensões de marcas com nomes carregados de significado, quando a similaridade percebida entre a extensão e a marca for baixa.

Já uma extensão com média similaridade não se beneficiaria de um nome carregado de significado porque o formato de varejo não é tão similar ao formato de varejo original e a associação não é imediata. Da mesma forma, um nome inventado não teria nenhuma contribuição para a categoria do novo formato, mas também não o prejudicaria. Logo, uma extensão de formato de varejo de média similaridade seria igualmente avaliada caso o nome fosse carregado de significado ou caso o nome fosse inventado. Isso leva à seguinte hipótese:

Hipótese 3 - Extensões de marcas em formatos de média similaridade percebida ao formato original serão igualmente avaliadas quando o nome da marca-mãe for inventado ou quando o nome da marca-mãe for carregado de significado.

\section{METODOLOGIA DA PESQUISA DE CAMPO}

Para testar as hipóteses propostas, os autores consideraram adequada a realização de uma pesquisa do tipo experimental e posterior análise quantitativa dos dados obtidos no campo.

Um experimento se caracteriza pela manipulação deliberada de algum aspecto da realidade a ser investigada e é utilizado para obter evidências de relação de causa e efeito 
(SOLOMON; TROUTMAN, 2003). Cooper e Schindler (2003) também entendem que em um experimento o pesquisador tenta controlar e/ou manipular as variáveis do estudo e que a técnica é apropriada quando se deseja descobrir se certas variáveis (independentes) produzem efeitos em outras variáveis (dependentes).

Pesquisadores da área de Marketing afirmam que, além da medição dos resultados, a pesquisa experimental pretende mostrar de que modo e por qual motivo um determinado fenômeno ocorre e que seu projeto deve contemplar a manipulação de uma ou mais variáveis, enquanto outras são mantidas constantes (GUERRING, 2001; BABBIE, 2006; MALHOTRA, 2006).

\subsection{FRAMEWORK DA PESQUISA}

O processo de elaboração da pesquisa descrita nesta seção contou com seis etapas principais, retratadas na Figura 1. Inicialmente, definiu-se, com base na literatura do tema, o problema de pesquisa e as hipóteses a serem testadas. Visando a responder a questão de pesquisa, os autores decidiram qual método seria utilizado, bem como qual seria a amostra necessária para a realização do experimento.

$\mathrm{Na}$ quarta etapa do planejamento, os autores definiram quais seriam as variáveis manipuladas - também chamadas de estímulos - para posterior desenvolvimento do instrumento de pesquisa. No caso específico, como a pretensão era estudar a relação entre extensão de nomes (carregados de significado e inventados) em formatos de estabelecimentos varejistas com diferentes graus de similaridade com o negócio original, ficou evidente que essas tipologias de nomes e diferentes formatos de lojas varejistas seriam os estímulos.

O quinto passo foi o desenvolvimento dos instrumentos de pesquisa, com as manipulações necessárias para que as hipóteses fossem testadas e, finalmente, após a aplicação do pré-teste (teste em um número reduzido de elementos da amostra), realizou-se a pesquisa de campo propriamente dita. 
Figura 1 - Etapas da elaboração da pesquisa

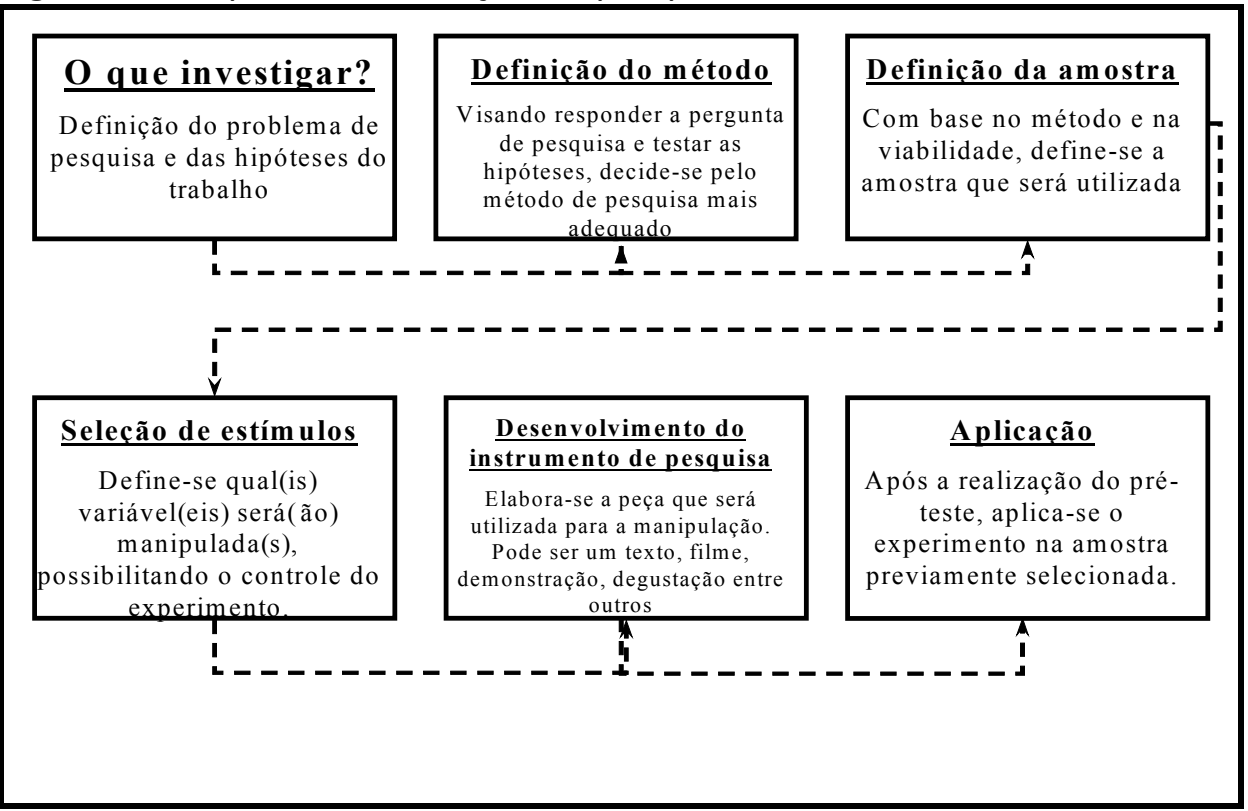

Fonte: elaboração dos autores (2012).

\subsection{AMOSTRA}

A amostra utilizada foi composta por alunos do curso de Administração de Empresas de uma grande universidade privada brasileira. Embora a opção por essa amostra não probabilística (MALHOTRA, 2006) tenha decorrido pela conveniência dos autores, a utilização de alunos se justifica por serem, geralmente, capazes de tomar suas próprias decisões de consumo e por possuírem as capacidades de assimilação e análise necessárias para a realização de um estudo experimental.

\subsection{SELEÇÃO DOS ESTÍMULOS}

Para a construção dos estímulos, realizou-se um processo de brainstorming, que possibilitou a escolha dos formatos varejistas do estudo. Definiu-se o formato homecenter para ser a base do experimento. Essa decisão se deve ao fato de esse formato de loja ter um modelo de atendimento bastante flexível, pois os clientes podem solicitar o atendimento de vendedores ou adquirir as mercadorias de maneira autônoma, à sua preferência. 
Solicitou-se a um grupo de estudantes universitários do curso de Administração de Empresas $(n=15)$, escolhidos aleatoriamente, que listasse diversos formatos varejistas. A lista foi submetida a um segundo grupo de alunos $(n=20)$, para que este analisasse os formatos varejistas da lista e os classificasse, em uma escala de dez pontos, em relação ao quanto esses formatos são similares a um homecenter, sendo 1 igual a nada similar e 10, muito similar. O resultado dessa classificação, demonstrado na Tabela 1, apontou para utilização do formato de loja de eletrodomésticos como altamente similar a um homecenter, o formato de loja de informática como de média similaridade percebida e de uma livraria como formato com baixa similaridade.

Tabela 1 - Avaliação de similaridade de formatos varejistas com um homecenter

\begin{tabular}{llllll}
\hline Formato & $\mathbf{N}^{\mathbf{0}}$ & Mínimo & Máximo & Média & Desvio padrão \\
\hline \hline Loja de Eletrodomésticos & 20 & 3 & 10 & 7,25 & 2,38 \\
\hline Loja de Cortinas & 20 & 1 & 10 & 5,75 & 3,25 \\
\hline Loja de Móveis & 20 & 1 & 10 & 5,65 & 3,64 \\
\hline Armarinhos & 20 & 1 & 10 & 5,30 & 3,04 \\
\hline Loja de Eletrônicos & 20 & 1 & 10 & 5,05 & 3,54 \\
\hline Mercado & 20 & 1 & 10 & 4,85 & 3,61 \\
\hline Loja de Produtos de Limpeza & 20 & 1 & 10 & 4,80 & 3,15 \\
\hline Autopeças & 20 & 1 & 10 & 4,80 & 3,39 \\
\hline Loja de Informática & 20 & 1 & 10 & 4,45 & 3,26 \\
\hline Loja de Artesanatos & 20 & 1 & 10 & 4,25 & 3,02 \\
\hline Concessionária de veículos & 20 & 1 & 10 & 4,10 & 3,33 \\
\hline Loja de 1,99 & 20 & 1 & 9 & 4,00 & 3,02 \\
\hline Loja de Roupas & 20 & 1 & 9 & 3,95 & 3,53 \\
\hline Distribuidora de água & 20 & 1 & 10 & 3,90 & 3,27 \\
\hline Floricultura & 20 & 1 & 8 & 3,85 & 2,85 \\
\hline Software House & 20 & 1 & 10 & 3,80 & 3,08 \\
\hline Loja de Artigos Esportivos & 20 & 1 & 9 & 3,80 & 3,20 \\
\hline Distribuidora de gás & 20 & 1 & 10 & 3,65 & 3,15 \\
\hline Loja de Celulares & 20 & 1 & 10 & 3,60 & 3,01 \\
\hline Livraria & 20 & 1 & 10 & 3,40 & 2,96 \\
\hline Fonte: dados da pesquisa & $1012)$ & & & & \\
\hline
\end{tabular}

Fonte: dados da pesquisa (2012).

Escolhidos os formatos varejistas que seriam utilizados na pesquisa de campo, passouse à criação dos nomes de estabelecimentos varejistas - carregado de significado e inventado que seriam aplicados aos dois formatos varejistas para a construção dos questionários. 
Novamente, foi utilizado o processo de brainstorming para escolha do nome carregado de significado. Após a filtragem das propostas, elegeu-se o nome CONSTRULAR como nome carregado de significado, por fazer alusão à construção civil, e lar, por trazer ideias intimamente ligadas a um homecenter.

Para escolha do nome inventado, utilizou-se o software MakeWords (disponível em: <http://www.makewords.com>), específico para geração de nomes e domínios em diversos idiomas. Foram gerados, por meio do software, oito nomes que foram submetidos a um terceiro grupo de alunos $(n=12)$, para que estes avaliassem, em uma escala de dez pontos, a possibilidade de aplicação do nome em qualquer formato de loja, sendo 1 - este nome não pode ser aplicado em qualquer formato de loja varejista, e 10 - este nome pode ser aplicado em qualquer formato de loja varejista. O nome inventado escolhido foi $\mathrm{ACION}$, e o resultado da análise realizada está demonstrado na Tabela 2.

Tabela 2 - Avaliação de possibilidade da aplicação do nome inventado em diversos formatos

\begin{tabular}{llll}
\hline Nome & $\mathbf{N}^{\mathbf{0}}$ & Média & Desvio padrão \\
\hline \hline Acion & 12 & 7,60 & 2,30 \\
Glapi & 12 & 5,60 & 3,05 \\
Vister & 12 & 5,20 & 3,56 \\
Factude & 12 & 4,80 & 3,56 \\
Walipe & 12 & 4,60 & 3,78 \\
Chron & 12 & 3,60 & 2,97 \\
Refer & 12 & 3,40 & 1,67 \\
Trafal & 12 & 3,20 & 2,28 \\
\hline
\end{tabular}

Fonte: dados da pesquisa (2012).

Após a seleção dos três formatos varejistas e dos três nomes, obtiveram-se seis combinações de extensão de marca, como demonstrado na Tabela 3. 
Tabela 3 - Seleção de estímulos

\begin{tabular}{lll}
\hline Estímulo escolhido & Tipo de nome & Similaridade \\
\hline Livraria Acion & Inventado & Baixa \\
Livraria Constrular & Carregado de significado & Baixa \\
Acion Eletrodomésticos & Inventado & Alta \\
Contrular Eletrodomésticos & Carregado de significado & Alta \\
Acion Informática & Inventado & Média \\
Constrular Informática & Carregado de significado & Média \\
\hline
\end{tabular}

Fonte: dados da pesquisa (2012).

Com o objetivo de testar as hipóteses concebidas na seção anterior, a etapa de seleção dos estímulos resultou na identificação de duas extensões de baixa similaridade com um homecenter, sendo uma com o nome inventado (Livraria Acion) e outra com nome carregado de significado (Livraria Constrular), duas extensões de alta similaridade, sendo uma com nome inventado (Acion Eletrodomésticos) e outra com nome carregado de significado (Constrular Eletrodomésticos) e, finalmente, duas extensões de média similaridade, com um homecenter sendo Acion Informática, classificada como nome inventado, e Constrular Informática, como um nome carregado de significado.

\subsection{PROCEDIMENTOS E MEDIDAS}

No momento da aplicação dos questionários, um dos seis estímulos, apresentados sob a forma de texto, foi apresentado aos elementos da amostra selecionada. O Quadro 1 exemplifica o estímulo utilizado para extensão de nome carregado de significado em formato com baixa similaridade.

Quadro 1 - Exemplo de estímulo utilizado na pesquisa de campo

Estamos assessorando uma grande rede de lojas de materiais para construção civil, sediada em São Paulo, que atualmente dispõe de 50 grandes homecenters na cidade. Trata-se da CONSTRULAR MATERIAIS PARA CONSTRUÇÃO. As lojas da CONSTRULAR MATERIAIS PARA CONSTRUÇÃO possuem todos os produtos necessários para construções e reformas residenciais, com boa variedade de opções e em grande quantidade, garantindo que todos os clientes sejam atendidos. As lojas contam, ainda, com excelente atendimento realizado pela equipe de vendas e por arquitetos especialmente contratados para auxiliar os clientes com sugestão de produtos. Os preços da CONSTRULAR

MATERIAIS PARA CONSTRUÇÃO são competitivos e os gerentes estão sempre disponíveis para ajudar os clientes em todas as suas necessidades.

Visando a diversificar sua atuação no mercado, este varejista está interessado em abrir uma nova livraria que se chamará LIVRARIA CONSTRULAR.

A LIVRARIA CONSTRULAR que será inaugurada, terá as mesmas características de qualidade existentes nas lojas de materiais para construção do grupo. 
Gostaríamos de ter sua avaliação da LIVRARIA CONSTRULAR. Todas as respostas são estritamente confidenciais e serão analisadas apenas de forma agregada. Não existem respostas certas ou erradas. A primeira impressão, normalmente, é a melhor resposta.

Fonte: elaboração dos autores (2012).

Após a leitura do estímulo, os participantes avaliaram as extensões de marca por meio de oito afirmativas (Apêndice 1). Três afirmativas mensuravam a atitude em relação à marca (Questões 3, 4 e 5), quatro itens mensuravam a intenção de utilização (Questões 1, 2, 7 e 8) e um item mensurava a similaridade percebida entre os formatos varejistas propostos e o original (livraria, loja de eletrodoméstico e loja de informática em relação a um homecenter) e estendido. As avaliações foram feitas utilizando-se uma escala de Likert de 5 pontos (variando de 1 - discordo totalmente, até 5 - concordo totalmente).

No final do questionário, foram solicitados alguns dados pessoais dos respondentes, visando a possibilitar a caracterização da amostra.

\subsection{CRITÉRIOS PARA ANÁLISE DOS DADOS}

Por se tratar de um experimento em desenho fatorial completo 3 (alta, média e baixa similaridade) $\times 2$ (nome carregado de significado e nome inventado) entre sujeitos, utilizou-se a técnica estatística de análise de variância multivariada (MANOVA), com nível de significância a $10 \%$ ( $p$-value $<0,10)$, por meio do software estatístico SPSS for Windows, versão 13.0.

O p-value (representado por " $p$ ") corresponde ao menor nível de significância que pode ser assumido para rejeitar a hipótese nula (hipótese de igualdade entre as observações). Dizemos que há significância estatística quando o $p$-value é menor que o nível de significância adotado (HAIR et al., 2005). Por exemplo, quando o nível de significância adotado é de $10 \%$ e o $p=0,001$, pode-se dizer que o resultado é bastante significativo, pois esse valor é muito inferior ao nível de significância determinado. Por outro lado, se $p=0,168$, o resultado não é significativo e, portanto, não há diferença entre as observações.

Utilizou-se, também, o SPSS for Windows para análise fatorial exploratória, com o intuito de validar a formação dimensional das avaliações de intenção e atitude. Os critérios para essa análise foram: extração de componentes principais com rotação ortogonal varimax, 
comunalidade mínima de 0,5, cargas fatoriais superiores a 0,5 e cargas cruzadas inferiores a 0,4. Também verificou-se o coeficiente de esfericidade de Barthett significativo e KMO mínimo de 0,7 (HAIR et al., 2005). Nessa fase, também se verificou a consistência interna dos itens por meio dos índices alfa de Cronbach, superiores a 0,7 (NUNNALLY, 1978).

\section{RESULTADOS OBSERVADOS}

Nesta seção, serão demonstrados os resultados obtidos na aplicação da pesquisa.

\subsection{PERFIL DA AMOSTRA}

A amostra foi composta por 170 estudantes universitários, sendo 105 mulheres $(61,8 \%)$ e 65 homens (38,2\%). Desse total, 129 (75,9\%) eram solteiros(as) e 33 (19,4\%), casados(as). A idade média dos pesquisados é de 25 anos $(\mathrm{dp}=6,44)$.

\subsection{COLETA E CODIFICAÇÃO DOS DADOS}

A coleta foi realizada durante o mês de maio de 2009. Os questionários foram distribuídos nas salas de aula e, como os diferentes estímulos foram distribuídos aleatoriamente, foi solicitado aos respondentes que não fizessem comentários durante a coleta dos dados. A quantidade de questionários respondidos por tipo de estímulo foi equilibrada, como demonstrado na Tabela 4.

Tabela 4 - Quantidade de questionários por tipo de estímulo

\begin{tabular}{llll}
\hline Estímulo & Frequência & $\%$ & \% acumulado \\
\hline \hline Livraria Constrular & 30 & 17,65 & 17,65 \\
Livraria Acion & 29 & 17,06 & 34,71 \\
Constrular Eletrodomésticos & 29 & 17,06 & 51,76 \\
Acion Eletrodomésticos & 29 & 17,06 & 68,82 \\
Constrular Informática & 27 & 15,88 & 84,71 \\
Acion Informática & 26 & 15,29 & 100,00 \\
\hline Total & 170 & 100 &
\end{tabular}

Fonte: dados da pesquisa (2012). 


\subsection{ANÁLISE DOS RESULTADOS}

A análise fatorial exploratória apontou para dois fatores distintos - intenção (alfa $=0,80)$ e atitude (alfa=0,74), como havia sido previsto. A variância total explicada foi de $63,78 \%$ e todos os indicadores foram adequados (KMO=0,804 e coeficiente de Barthett significativo a $\left.1 \%\left[\mathrm{c}^{2}=362,90 ; 21 \mathrm{gl}, \mathrm{p}<0,01\right]\right)$.

Tabela 5 - Análise fatorial exploratória dos itens de avaliação

\begin{tabular}{llll}
\hline Afirmativas & Atitude & Intenção & Comunalidade \\
\hline \hline Q1 & $\mathbf{0 , 7 1 5}$ & 0,278 & 0,588 \\
Q2 & $\mathbf{0 , 6 9 1}$ & 0,251 & 0,541 \\
Q3 & 0,165 & $\mathbf{0 , 8 4 9}$ & 0,748 \\
Q4 & 0,224 & $\mathbf{0 , 8 2 2}$ & 0,726 \\
Q5 & 0,214 & $\mathbf{0 , 7 8 9}$ & 0,668 \\
Q7 & $\mathbf{0 , 6 7 6}$ & 0,125 & 0,573 \\
Q8 & $\mathbf{0 , 8 4 2}$ & 0,114 & 0,721 \\
\hline Variância explicada (\%) & $\mathbf{4 6 , 8 4 3}$ & 16,940 & \\
Alfa de Cronbach & 0,74 & 0,80 & \\
\hline \multicolumn{4}{l}{ Fonte: dados da pesquisa (2012). } \\
\end{tabular}

Como era esperado, houve diferença significativa na avaliação da similaridade percebida entre os 3 formatos propostos e o formato original $(F(164,5)=11,61 ; p<0,01)$. 0 teste de manipulação da similaridade apontou maior similaridade entre uma loja de eletrodomésticos e um homecenter $(M=3,14$ e 3,24$)$ do que entre uma livraria e um homecenter $(M=1,97$ e 2,03). Do mesmo modo, o formato de loja de informática apontou para uma similaridade percebida intermediária ( $M=2,65$ e 2,81), como indicado na tabela 6. 
Tabela 6 - Teste de comparação de médias da similaridade entre o formato estendido e o formato original

\begin{tabular}{l|l|l|l|l|l|l|l}
\hline Estímulo & $\mathbf{N}^{\circ}$ & Média & $\begin{array}{l}\text { Desvio } \\
\text { padrão }\end{array}$ & \multicolumn{2}{l|l}{$\begin{array}{l}\text { Intervalo de 95\% de } \\
\text { confiança para média }\end{array}$} & \multicolumn{2}{|c}{ Valores observados } \\
\hline & & & & $\begin{array}{l}\text { Limite } \\
\text { inferior }\end{array}$ & $\begin{array}{l}\text { Limite } \\
\text { superior }\end{array}$ & Mínimo & Máximo \\
\hline Livraria Constrular & 30 & 2,03 & 0,67 & 1,78 & 2,28 & 1,00 & 3,00 \\
\hline Livraria Acion & 29 & 1,97 & 0,73 & 1,69 & 2,24 & 1,00 & 3,00 \\
\hline $\begin{array}{l}\text { Constrular } \\
\text { Eletrodomésticos }\end{array}$ & 29 & 3,24 & 1,09 & 2,83 & 3,66 & 1,00 & 5,00 \\
\hline Acion Eletrodomésticos & 29 & 3,14 & 0,88 & 2,81 & 3,47 & 2,00 & 5,00 \\
\hline Constrular Informática & 27 & 2,81 & 0,88 & 2,47 & 3,16 & 1,00 & 5,00 \\
\hline Acion Informática & 26 & 2,65 & 0,85 & 2,31 & 3,00 & 1,00 & 5,00 \\
\hline
\end{tabular}

Fonte: dados da pesquisa (2012).

Esse resultado indica que a etapa de seleção dos estímulos obteve sucesso, pois a diferença estatisticamente significativa da percepção dos níveis de similaridade entre os formatos ficou alinhada com o objetivo dos cenários desenvolvidos.

Em seguida, realizou-se o teste das hipóteses propostas.

\subsubsection{Teste das hipóteses}

Na formulação do teste de análise de variância multivariada, foram incluídos os fatores relacionados à similaridade (alta, baixa e mediana) e extensão (nome carregado de significado e nome inventado) e, como variáveis dependentes, a atitude em relação à extensão de marca e a intenção de uso. Para ambos os casos, esperava-se a identificação de um efeito principal da similaridade e da extensão e um efeito de interação entre similaridade e extensão.

O resultado da técnica estatística Manova para atitude em relação à extensão de marca proposta apontou para um efeito principal para a similaridade $(F(164,2)=37,73 ; p<0,01)$ e um efeito principal para a extensão $(F(164,1)=3,81 ; p<0,1)$. $O$ resultado apontou também para um efeito de interação entre similaridade e extensão significativo $(F(164,2)=35,96 ; p<0,01)$.

Como havia sido previsto, a atitude em relação à extensão de marca carregada de significado foi maior para formatos de alta similaridade $(M=3,46)$ do que para formatos de média similaridade $(M=3,27)$, e significativamente maior do que para formatos de baixa similaridade 
(M=1,95). Também, como havia sido previsto, a atitude em relação à extensão de marca inventada é maior quando aplicada em formatos não similares $(M=2,60)$, frente a formatos de alta similaridade $(\mathrm{M}=2,22)$. Essas relações podem ser observadas no Gráfico 1.

Gráfico 1 - Relação entre atitude, tipo de nome e similaridade da extensão

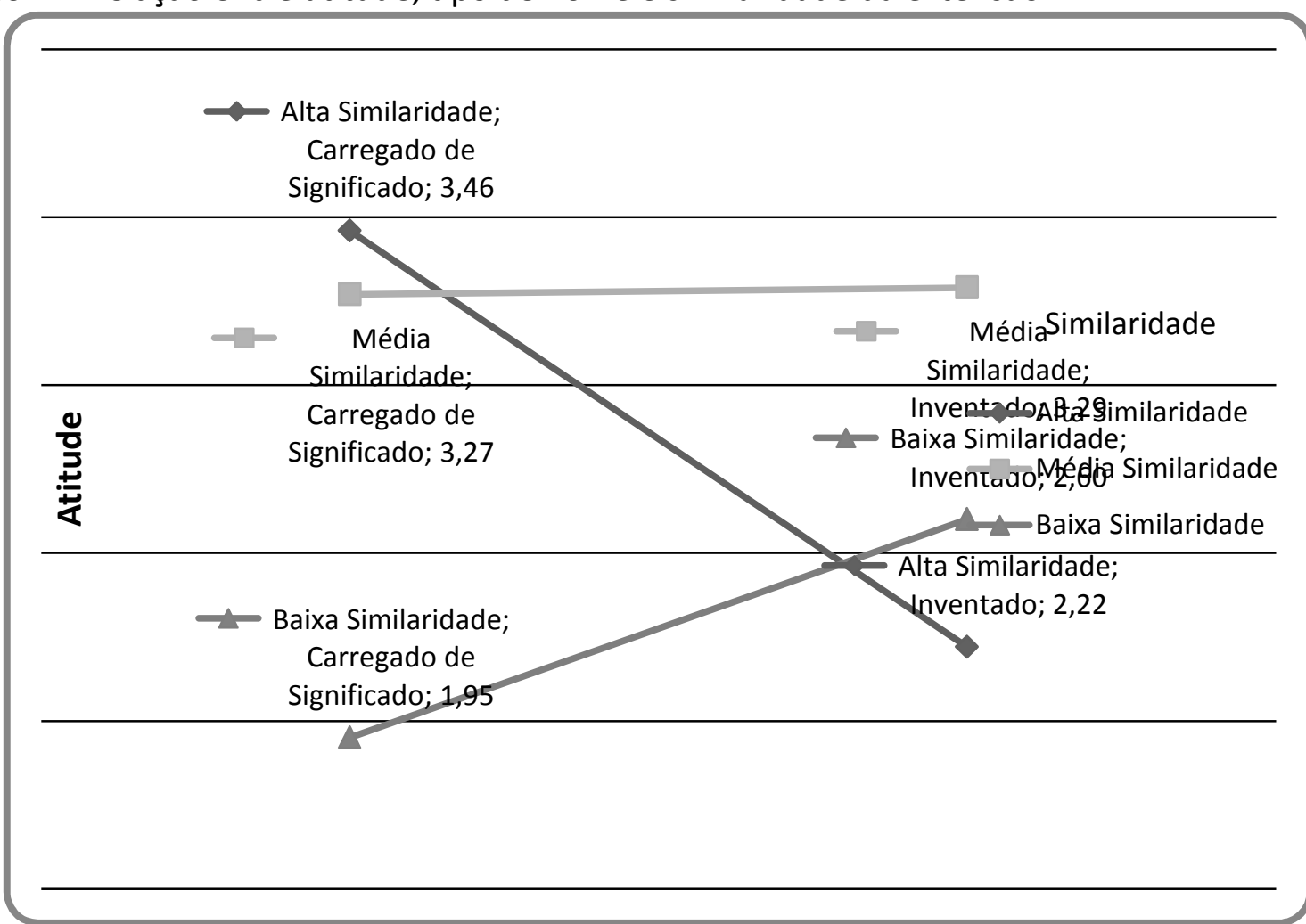

Fonte: dados da pesquisa (2012).

Do mesmo modo, o resultado da técnica estatística Manova para intenção em relação à extensão de marca apontou um efeito principal para a similaridade $(F(164,2)=37,73 ; p<0,01)$ e um efeito principal para a extensão $(F(164,1)=3,81 ; p<0,1)$. Todavia, diferente do que se esperava, não foi observado nenhum efeito de interação entre similaridade e extensão $(F(164,2)=0,11 ; n$.s.).

A intenção em utilizar o varejista é maior para o formato de alta similaridade, não importando se a extensão ocorreu em marca carregada de significado $(M=3,66)$ ou inventada $(M=3,90)$. A intenção foi menor para o formato de baixa similaridade (carregado de significado $M=2,44$ e inventado $M=2,53$ ). Por fim, a intenção ocupou posição intermediária para o formato de média similaridade, não importando se a extensão aconteceu em uma marca carregada de significado $(M=3,41)$ ou em uma marca inventada $(M=3,64)$, como demonstrado no Gráfico 2 . 
Gráfico 2 - Relação entre intenção, tipo de nome e similaridade da extensão

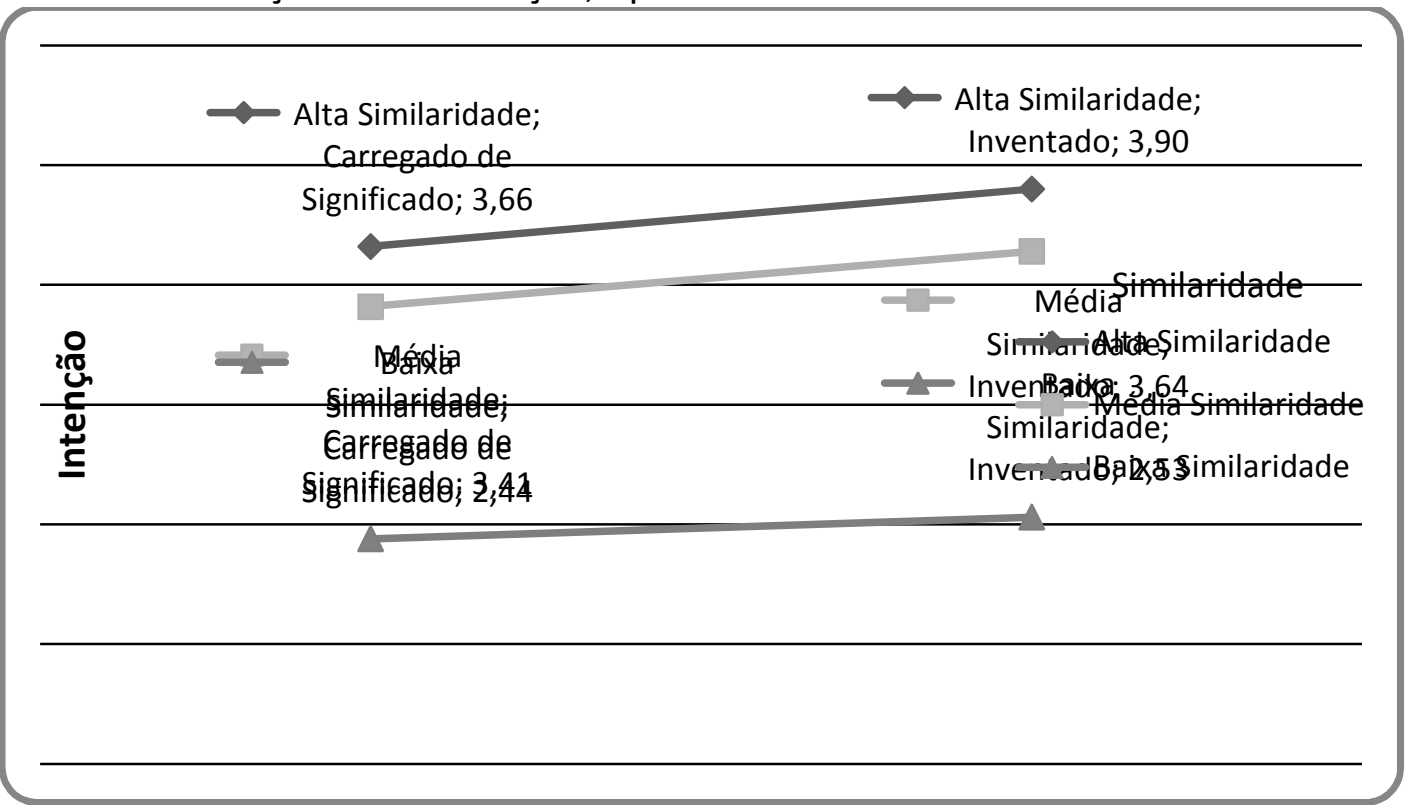

Fonte: dados da pesquisa (2012).

Os resultados observados não permitem que se rejeite integralmente nenhuma das hipóteses testadas. Como havia sido previsto, a extensão de alta similaridade foi mais bem avaliada quando estava sendo considerado um nome carregado de significado. Contudo, o mesmo fenômeno não foi observado quando a variável dependente era a intenção. Nesse cenário, a intenção acompanhou o nível de similaridade da extensão, não importando o tipo de nome utilizado.

\section{CONCLUSÕES, IMPLICAÇÕES E LIMITAÇÕES DESTA PESQUISA}

Este trabalho teve por objetivo estudar a extensão de marca em estabelecimentos varejistas, especificamente na utilização de nomes inventados e carregados de significado em formatos varejistas de alta, média e baixa similaridade percebida em relação ao formato original. Para tanto, foi conduzido um experimento junto aos alunos de Administração de Empresas, cujos resultados suportaram as hipóteses propostas.

Uma das indicações deste estudo aponta que a utilização de extensão de marcas para formatos com baixa similaridade em relação ao formato varejista original tende a carregar maior risco de rejeição dos consumidores. Portanto, recomenda-se aos gestores de marketing cautela 
nessa estratégia de extensão de marca, pois apenas a utilização de um nome inventado considerado aplicável em amplo espectro de formatos - teve avaliação positiva nesse tipo de aplicação.

A utilização de nome carregado de significado não parece ser adequada para extensão em formatos com baixa similaridade em relação ao formato original. Embora alguns varejistas tenham adotado a estratégia de estender suas marcas para formatos totalmente diferentes daquele com o qual opera, essa prática pode depender fortemente da reputação que a marca já possui junto de sua clientela. Recomenda-se que as pequenas operações, ou os varejistas com menor tradição no mercado, ponderem se a extensão do nome é a melhor alternativa.

A extensão de nome carregado de significado se mostrou uma boa opção para novos negócios similares ao formato original do varejista. Como essa opção recebeu a melhor avaliação dos pesquisados, reforçou a viabilidade da adoção dessa estratégia.

Uma das contribuições desta pesquisa foi a identificação da avaliação intermediária da extensão de marcas carregadas de significado e inventadas em formatos de média similaridade percebida. Essa estratégia de naming pode ser uma alternativa aos gestores e praticantes de marketing na utilização de extensões de marcas em situações de média similaridade, com o intuito de minimizar os riscos inerentes ao início de novas atividades comerciais.

Outro ponto interessante levantado neste estudo foi o comportamento da intenção e da atitude declarada pela amostra. Aparentemente, um nome inventado causa certo estranhamento, que pode ser observado no nível atitudinal, mas que, no entanto, não influencia a intenção no primeiro momento. Todavia, é possível que esse estranhamento possa conduzir à intenção menos favorável quando a situação for mais específica.

A característica da amostra utilizada constitui uma das limitações deste trabalho. A natureza não probabilística impede a generalização dos resultados, e o corte transversal utilizado na coleta de dados sugere que os resultados obtidos devam ser considerados sob a ótica das características específicas da amostra utilizada. Portanto, recomendam-se replicações deste estudo com a utilização de amostras aleatórias, preferencialmente formadas por outros atores sociais que não sejam estudantes, já que esse grupo tem a tendência de maior homogeneidade de posicionamento se comparado a outros grupos sociais (PETERSON, 2001). 
Outra limitação deste estudo é a utilização de marcas fictícias. Se por um lado a utilização de marcas fictícias elimina o viés que pode ser causado por lembranças ou experiências passadas dos respondentes, por outro pode afetar a validade externa do estudo (HERNANDEZ et al., 2011). Portanto, um estudo comparativo com os dois tipos de marca (real e fictícia) seria interessante.

\section{CONSIDERAÇÕES FINAIS}

Esta pesquisa representa uma iniciativa exploratória, no sentido de auxiliar a tomada de decisão dos praticantes de marketing, no tema de extensão de marcas para estabelecimentos varejistas.

Mesmo que o senso comum indique que a extensão de marca em formatos de alta similaridade seja uma estratégia adequada, pouco se tinha observado sobre a influência do tipo de nome estendido na avaliação, ou mesmo como a avaliação do consumidor era influenciada pelos diferentes níveis de similaridade percebida.

É razoável admitir que o perfil da amostra pode ter ocasionado certa influência nos resultados. Contudo, acredita-se que este estudo contribui para o entendimento de um fenômeno mercadológico ainda pouco estudado, tanto no Brasil quanto internacionalmente.

A teoria sugere que a marca de um estabelecimento varejista pode conferir diferenciação deste em relação aos outros players do mercado, e este estudo reforça o naming como mecanismo para alavancar a avaliação geral de uma loja, aumentando a probabilidade de utilização do estabelecimento por parte dos consumidores.

Contudo, os autores acreditam que outras estratégias do marketing mix não podem ser colocadas de lado pelos gestores. Políticas de preços, promoções e relacionamento com seus consumidores devem atuar conjuntamente com a estratégia de branding, visando a garantir poder competitivo aos operadores nesse disputado canal de distribuição.

Nota: os autores agradecem aos avaliadores anônimos do periódico pelas contribuições realizadas para a melhoria deste artigo. 


\title{
BRAND EXTENSION STRATEGY PERCEPTION IN COMMERCIAL ESTABLISHMENTS: WHAT'S THE BEST NAME FOR A STORE?
}

\begin{abstract}
The main objective of this study is verify the effect that different strategies of brand name attribution (descriptive or invented) exercises on retail brand extensions more or less similar. This research is justified not only by the absence of studies on retail brand extensions but also by the recurrence with which this strategy has been happening in our society. The formulated hypotheses were tested by an experiment, in full factorial design 3 (high, medium and low similarity between original and extended retail format) $\times 2$ (descriptive name and invented name) among subjects involving 170 respondents. The result of this study that the utilization of name that is full of meaning does not seem appropriate to extension in formats with low similarity to the original format and that the extension off meaning-full name is a good option to new deals similar to the retailer's original format
\end{abstract}

Key Words: Brand extension. Retail. Similarity.

\section{REFERÊNCIAS}

AAKER, D.A. Brand equity: gerenciando o valor da marca. São Paulo: Negócio, 1998.

AAKER, D.A.;. KELLER, K. L. Consumer evaluations of brand extensions. Journal of Marketing, v. 54, p. 27-51, 1990.

AMA - American Marketing Association. Disponível em: <http://www.marketingpower.com/_layouts/Dictionary.aspx?dLetter=B>. Acesso em: 03 jun. 2009.

BABBIE, E. R. The practice of social research. 11. ed. Belmont: Wadsworth Publ., 2006

BOUSH, D.; SHIPP, S.; LOKEN, B.; GENCTURK, E.; CROCKETT, S.; KENNEDY, E.; MINSHALL, B.; MISURELL, D.; ROCHFORD, L.; STROBEL, J. Affect generalization to similar and dissimilar brand extensions Psychology and Marketing, Fall, n. 4, vol. 3 p. 225-237, 1987. 
CHEN, K.J.; LIU, C. M. Positive brand extension trial and choice of parent brand. Journal of Product and Brand Management, Nov. v. 13, n. 1, p. 25-36, 2004.

COOPER, D. R.; SCHINDLER, P. S. Métodos de pesquisa em administração. Porto Alegre: Bookman, 2003.

FREE, C. Building a financial brand you can bank on. Journal of Brand Management, Nov. v. 24, n. 1, p. 29-34, 1996.

GERRING; J. Social science methodology: a criterial framework. Cambridge: Cambridge University Press, 2001.

HAIR, J. F. et al. Análise Multivariada de Dados. Porto Alegre: Bookman, 2005

HERNANDEZ, J. M. C. et al. Extensão de Marcas Corporativas de Serviços. RAC, Curitiba, v. 15, n. 4, art. 1, pp. 561-579, jul./ago. 2011.

KAPFERER, J. N. As marcas, capital da empresa: criar e desenvolver marcas fortes. Porto Alegre: Bookman, 2003.

KELLER, K. L. Conceptualizing, Measuring, and Managing Customer-Based Brand Equity. Journal of Marketing, Jan. v. 57, p. 1-22, 1993

. Strategic Brand Management: Building, Measuring, and Managing Brand Equity. PrenticeHall: New Jersey, 1998.

Strategic Brand Management: Building, Measuring, and Managing Brand Equity. New York: Prentice Hall, 2003

. HECKER, S. E.; HOUSTON, M. J. The effects of brand name suggestiveness on advertising recall. Journal of Marketing, Jan. v. 62, n. 1, p. 48-57, 1998.

. MACHADO, M. Gestão estratégica de marcas. São Paulo: Pearson Prentice Hall, 2006. KOHLI, C.; SURI, R. Brand names that work: a study of the effectiveness of different types of brand names. Marketing Management Journal, Fall/Winter, n. 10 vol. 2, , p.112-120, 2000.

; HARICH, K.; LEUTHESSER, L. Creating brand identity: a study of evaluation of new brand names. Journal of Business Research, November, n. 58 vol. 11, p. 1506-1515, 2004.

MALHOTRA, N. K. Pesquisa de marketing: uma orientação aplicada. São Paulo: Bookman, 2006. 
MARQUI, A.C.; BATALHA, M.O.; URDAN, F.T. Gestão de marcas - estudo multicaso em empresas da indústria de alimentos. In: XXVII ENCONTRO NACIONAL DE ENGENHARIA DE PRODUÇÃO, 17., 2008, Rio de Janeiro. Anais eletrônicos... Rio de Janeiro: 2008. disponível em: http://scholar.google.com.br/scholar?q=Gest\%C3\%A3o+de+marcas+\%E2\%80\%93+estudo+multica so+em+empresas+da+ind\%C3\%BAstria+de+alimentos.+In\%3A+XXVII+ENCONTRO+NACIONAL+DE+ ENGENHARIA+DE+PRODU\%C3\%87\%C3\%830\&btnG=\&hl=pt-BR\&as_sdt=0\%2C5, último acesso em 28/04/2013.

MELTON, R.J. Basic Objects in Natural Categories. Cognitive Psychology, n. 8 vol. 3, pp. 382-439, 1979 In: KOHLI, C.; HARICH, K.; LEUTHESSER, L. Creating brand identity: a study of evaluation of new brand names. Journal of Business Research, November, n. 58 vol. 11, p. 1506-1515, $2004 .$.

MILEWICZ, J.; HERBIG, P. Evaluating the brand extension decision using a model of reputation building. Journal of Product and Brand Management, v. 3, p. 39- 47, 1994.

MORRIN, M. The impact of brand extensions on parent brand memory structures and retrieval processes. Journal of Marketing Research, Nov. n. 4, v. 36, p. 517-525, 1999.

MOUTINHO, L. C.; COIMBRA, R.L. O nome é a alma do negócio: estudo linguístico dos nomes das lojas em Portugal. In: XIII ENCONTRO DA ASSOCIAÇÃO PORTUGUESA DE LINGUÍSTICA, II., 1998, Lisboa. Anais... Lisboa: Colibri, 1998. p. 93-104.

NUNNALLY, J.C. Psychometric Theory. 2. ed. New York: McGraw, 1978.

SWAMINATHAN, V.; FOX, R. J.; REDDY, S. K. The impact of brand extension on choice. Journal of Marketing, Fall, v. 65 n. 3, p. 1-15, 2001.

OLIVEIRA, B.A.C.; MATTAR, F.N. Um estudo acerca das estratégias de extensões de marca e de linha de produtos. RAM - Revista de Administração Mackenzie,Julho-Dezembro, v. 2, n. 2, p. 39$54,2000$.

PARK, C. W.; MILBERG, S.; LAWSON R. Evaluation of brand extensions: the role of product feature similarity and brand concept consistency. Journal of Consumer Research, Set . v. 18 n.2, p. 185193, 1991.

PETERSON, R. A. On the use of college students in social science research: insights from a secondorder meta-analysis. Journal of Consumer Research, Dez. n. 28 vol. 3, p. 450-461, 2001.

RIBEIRO, M. Explorando os limites da extensão de marcasRevista de Administração Mackenzie, Julho-Setembro, vol. 7 n. 3, p. 90-111, 2006

SMITH, D. C.; PARK, C. W. The effects of brand extensions on market share and advertising efficiency. Journal of Marketing Research, Ago. v. 29, n.3, p. 296-313, 1992. 
SOLOMON, I.; TROUTMAN, K. T. Experimental judgement and decision research in auditing: The first 25 years of AOS. Accouting, Organizations and Society. Maio, v. 28 n. 4, p. 395-412, 2003.

SULLIVAN, M. W. Brand extensions when to use them. Management Science, Junho, v. 38, Issue 6, p. 793-806, 1992.

SWAMINATHAN, V. Sequential brand extensions and brand choice behavior. Journal of Business Research, Junho, v. 56, n. 6, p. 431-442, 2003.

. FOX, R. J.; REDDY, S. K. The impact of brand extension introduction on choice. Journal of Marketing, Outubro, v. 65 n. 4, p. 1-15, 2001.

VELOSO, A.R. Extensão de marca e a percepção de risco do consumidor, In: SEMINÁRIOS DE ADMINISTRAÇÃO (SEMEAD), 4., 2003, p.1-16, São Paulo. Anais... São Paulo: USP, 2003.

VÖLCKNER, F.; SATTLER, H. Drivers of brand extension success: a structural equation modelling approach. Research Papers on Marketing and Retailing, Hamburgo, Fevereiro, v. 018 n.1/2, p. 147, 2004.

ZHANG, S.; SOOD, S.; "Deep" and "Surface" Cues: brand extension evaluations by children and adults. Journal of Consumer Research, Junho, v. 29 Issue 1, p. 129-141, 2002.

\section{APÊNDICE 1 - VARIÁVEIS DA PESQUISA}

Q1 - Esta livraria <loja de eletrodomésticos/loja de informática> será viável.

Q2 - Esta livraria < loja de eletrodomésticos/loja de informática> é melhor do que a que frequento atualmente.

Q3 - Eu certamente compraria nesta livraria <loja de eletrodomésticos/loja de informática>.

Q4 - Eu certamente recomendaria esta livraria <loja de eletrodomésticos/loja de informática> para parentes e/ou amigos.

Q5 - Eu compraria mais nesta livraria <loja de eletrodomésticos/loja de informática> do que na que frequento atualmente.

Q6 - Este livraria <loja de eletrodomésticos/loja de informática> é parecida com uma loja de materiais para construção civil.

Q7 - A marca desta livraria <loja de eletrodomésticos/loja de informática> me traz lembranças e sentimentos muito bons.

Q8 - A qualidade desta livraria <loja de eletrodomésticos/loja de informática> é excelente. 